\title{
The System of Contributions for Health Insurance Scheme in Albania - Performance and main Challenges
}

PhD. Zamira Sinaj ${ }^{1}$

Florid Dumi²

Prof Assoc Dr. Alba Robert Dumi ${ }^{3}$

${ }^{1}$ PhD Candidate, Administration Department \& Health Care Hospital, Vlora Region, Albania, z.sinaj@yahoo.it ${ }^{2}$ Youth Exchange "Do it with Love" coordinator, BE office, floriddumi1@gmail.com 3Prof Assoc Dr, Dean of Graduated School, Management and Administration Department, Economy Faculty, University "Ismail Qemali" of Vlore, L Pavaresia, Sheshi: Skele, Vlore, Albania, alba.besi12@gmail.com

\section{Doi:10.5901/jesr.2014.v4n4p0289}

\begin{abstract}
Albanian health care system is undergoing comprehensive changes. The paper focuses on the system of contributions for health insurance scheme. The paper will argue the need for immediate measures regarding this issue. Based on the primary and secondary data, through an economic analysis is studying the trend of contributor's number for five years. Are identified the economic, social and political factors, that affect this process and whole health insurance scheme (HIS). In Albania, partly scheme function, an informal labor market, lack of incentives for participation in health scheme, weak administration capacity for contributions collecting and poor structure, regulatory and supervisor and all in all its funding challenges, are the main factors that accompanies for years the health care system and as the result the contributions system for health insurance. The main economic factor is a little economic growth and a problem with which Albania has already begun to face nowdays. In this paper research we want to present the new low reforming in health care system in Albania.Like any robust reform process, we face significant challenges across a spectrum of efforts. Designing country strategies was more time and labor intensive than originally anticipated, particularly because a large number of partners were engaged in the process to determine tough trade-offs. The Albanian Health sector is in the continuing transformation in the function of the realization of the proper standards. To realize the reform in this sector and to help the decision makers in their decision is necessary to have the right information on the source of the financing of health sector, on the destination of the expenditure in this sector and their control. "The establishment of the National Health Service is an integral part of the new Government program and it is also the fairest intervention intended to upgrade the system of service financing at the levels required by providers and recipients of health services.
\end{abstract}

Keywords: Public administration, Albanian strategy, Health sector, National service, Progress in health service

\section{Introduction}

The health sector is defined as the priority sector in the Albanian Strategy for the social and economic development. (Source: Charles Wright, March 2013) It's a key step in cultivating USAID's own "next generation" of leaders and to ensuring programs move forward on the path to a sustainable development future. Each new U.S. staff member is assigned both a Foreign Service National and an American mentor upon arrival at the mission. This customized program has harnessed the longstanding wealth of experience of many of our veteran Foreign Service Nationals - many with over 25 years of service at USAID-and empowered them to assume a leadership role within the Mission. Today, senior Foreign Service Nationals are taking the lead in mentoring new staff in effective government-to-government and monitoring and evaluation efforts.

As a result, new staff learn country-specific development challenges more quickly and can make more informed programming decisions.11staff were included in new mentoring programs this year, our challenge in the year ahead is to better target our programs to meet the specific needs of staff at all levels. New programs, from mentoring to training to individual consulting support, can help support our next generation of development leaders, no matter where they are from. Which challenge deserves the highest priority - providing universal access; instituting better measures of quality and outcomes and better management systems; or reining in costs? How should these challenges be addressed? What keeps us from "having it all"? Does the fundamental obstacle lie in market behavior, inadequate or asymmetric information, lack of( political will, or the human psyche?

\subsection{Public Services and the importance of development}

How would the proposed reforms tackle the underlying issue and help us maintain a sustainable balance between health care access, quality and cost - and between our health care goals and other important policy objectives - in future years? In the year ahead, we will continue to prioritize the development of country strategies and enable better coordination with our partners to reconcile competing priorities and focus on areas where we each have a comparative advantage. Our effort to focus our assistance programs has been successful for the past two years either because we successfully exited from sustainable projects or because our programming was too minimal to have a true impact. As we look ahead, we must continue to make tough choices and use each country's strategy as the backbone for decision-making to ensure the greatest development impact. (Arieh Goldman 2011) 


\subsubsection{Public Services in USA, one good experience for Albania}

This policy panel will present and debate proposals for the next steps in reforming the U.S. health care system. The good news is that almost all jurisdictions and professional bodies in Canada are beginning to take the quest for measureable high quality care seriously, albeit with emphasis on different aspects of the task and with varying degrees of success. There is marked but unsurprising inconsistency across the country, with its quasi-independent provincial jurisdictions and the silos of professional and organizational interests, but the report just released by the Health Council. It presents an interesting snapshot of the good intentions and the good ideas that are being pursued. The quality agenda in any health care system also has to deal with the insatiable demand for more and more expensive services - services that often bring a very small benefit at huge cost. There are serious questions about just how necessary all the current consultations, tests, prescriptions and procedures really are and these questions must be answered on the basis of rigorous evidence rather than tradition, belief systems or vested interests. Sustainable affordability means that value for money is very much a quality issue because of what is called the "opportunity cost" of any publicly provided health service, namely the alternative use of the money that could bring much greater benefit to more people.

These issues provide ample fodder for debate among the health care professions, the politicians and the public alike, but we cannot continue to avoid them. The U.S. health care system is the subject of much polarizing debate. At one extreme are those who argue that Americans have the "best health care system in the world", pointing to the freely available medical technology and state-of-the-art facilities that have become so highly symbolic of the system. At the other extreme are those who berate the American system as being fragmented and inefficient, pointing to the fact that America spends more on health care than any other country in the world yet still suffers from massive un-insurance, uneven quality, and administrative waste. (Bill Saporito 2006)Understanding the debate between these two diametrically opposed viewpoints requires a basic understanding of the structure of the U.S. health care system. This primer will explain the organization and financing of the system, as well as place the U.S. health care system in a greater international context. (www.mdindiaonline.com)

\subsection{The purpose of this study}

This study empirically examines the impact of organization of health care system, we are using the regression analyze of health data, the new experiences and information. As with all other countries, there are both private and public insurers in the Albanian health care system. What is unique about the U.S with Albanian implementation reforms? The system of health care, in the world is the dominance of the private element over the public element. The new residents and their associated activities will require a variety of services pro-vided by the areas public and private institutions. A social impact assessment must determine the quantity and variety of anticipated needs. The goods and services most commonly included in a social evaluation are open space and parks; cultural and recreation facilities; education; health care; special care for the elderly, the disabled, the indigent and preschool-age children; police and fire protection; and a variety of administrative support functions. The optimum amount of resources that would be required for the satisfaction of needs is based on either planning standards, which are guidelines established by professional organizations and government agencies, or service levels, which are observed national (or regional) average amounts of resources expended per capita or some unit of size.

\subsection{The study and indicators of services in health care system}

Service resources are objective indicators of the level of resources available for the satisfaction of society's needs. For example, the number of physicians, dentists, acute-care hospital beds, and psychiatric care hospital beds are indicators of the level of health care resources. Square feet of parkland, picnic areas, tot lots, etc., are indicators of facilities for recreation needs.

\section{Literature Review and Hypotheses}

\subsection{Health spending and financing}

The United States spent 15\% of its GDP on health care in 2003, the highest percentage in the OECD (an organization of industrialized countries). The average percentage of GDP spent on health care in OECD countries was $8.6 \%$. The United States also spends more on health care per capita than any other OECD country. In 2003 , total health spending per capita was $\$ 5,635$ US dollars (adjusted for purchasing power parity), more than twice the OECD average of $\$ 2,307$ US dollars. The diseases, treatments and surgeries under the broad based specialties approved under the New Health Insurance Scheme, 2012 year. (www.mdindiaonline.com)

In addition to these hospitals, the employee families will be also eligible for treatment in other institutions to be approved by the Insurance Company and Third Party Administrator. The Nodal Officers of the United India Insurance Company Limited situated in the District Headquarters and Toll Free Helpline Number are listed in the Annexure-IV. The lists of approved treatments and surgeries, approved hospitals and the addresses of the Offices situated in the District Headquarters are also hosted on the websites (www.tn.gov.in/departments/finance.html), Between 1998 and 2003, health spending per capita in the United States increased in real terms by $4.6 \%$ per year on average, a growth rate comparable to the OECD average of $4.5 \%$ per year. 


\subsubsection{Financial control and cost calculation systems}

The public sector is the main source of health funding in all OECD countries, except for the United States, Mexico and Korea. In the United States, $44 \%$ of health spending is funded by government revenues, well below the average of $72 \%$ in OECD countries. In the United States, private insurance accounts for $37 \%$ of total health spending, by far the largest share among OECD countries. Canada, France, and the Netherlands also have a relatively large share of funding coming from private insurance (more than 10\%).

\subsubsection{Health status and risk factors}

The paper aimed at addressing the issues associated with the non-diversified systemic risk, as an inherent endemic risk within Albanian financial system, caused by the monoline bank-based development approach, implemented since the fall of communism. The paper suggests, inter alia, the need to develop capital market and long-term instruments, especially corporate bonds. The Albanian economy needs to ensure a sustained economic development, which calls for a more balanced and competitive development of its financial system, based on a two-pillar approach (bank and nonbank sector) and the presence of capital market and the development of long-term instruments.

\subsubsection{Health status and risk factors in development countries}

Most OECD countries have enjoyed large gains in life expectancy over the past 40 years. In the life expectancy at birth increased by 7.3 years between 1960 and 2002, which is less than the increase of 14 years in life expectancy in Japan, or of 8.4 years in Canada. In 2002/3, life expectancy in the United States stood at 77.2 years, below the OECD average of 77.8 years. Japan, Iceland, Spain, Switzerland and Australia were among the top 5 countries registering the highest life expectancy among OECD countries. Infant mortality rates in the United States have fallen greatly over the past few decades, but not as much as in most other OECD countries. In 2002, the infant mortality rate in the U.S. was 7 deaths per 1,000 live births, above the OECD average of 6.1. Among OECD countries, infant mortality is the lowest in Japan and in the Nordic countries (Iceland, Sweden, Finland and Norway), which all have infant mortality rates below 3.5 deaths per 1,000 live births.(Source: Kao-Ping Chua AMSA Jack Rutledge Fellow 2005-2006 February 10, 2006)

\section{Methodology and Research Goal}

The Economics of Public Health Care Reform in Advanced and Emerging EconomiesPublic administration reform is another key priority of the Opinion. The adoption in May of the Civil Service Law, one of the measures required for obtaining candidate status, was a major step towards de-politicising public administration. The law, entering into force in October, is essential for building a professional, effective and merit-based public administration. It aims to create a consistent legal framework comprising state administration, independent institutions and local government units. It provides a clear classification of civil servants, formally establishes a top-level management civil servants corps and provides the basis for a transparent recruitment and promotion system. (USAID, Albanian Reform 2013,pp 13)

The law abrogates existing legislation without providing the necessary transitory provisions until its implementing legislation enters into force; the government approved in September 2013 technical amendments to avoid this legal vacuum. Timely adoption of the secondary legislation compliant with the principles of the law and proper implementation is essential. The Law on General Administrative Procedures is still pending. (Commission working document, Albania Brusel 2014)

\subsection{The development experiences in Albania and long term care needs.}

The term health insurance is commonly used in Albania to describe any program that helps pay for medical expenses, whether through privately purchased insurance, social insurance or a social welfare program funded by the government. ${ }^{[1]}$ Synonyms for this usage include "health coverage," "health care coverage" and "health benefits." Health care costs have been growing rapidly in the past several decades. Since 1970, total real per capita health spending has increased fourfold, while spending as a share of GDP has increased from 6 percent to 12 percent in advanced economies. In emerging economies, total health spending has increased from below 3 percent of GDP to 5 percent. These increases have put great fiscal pressure on governments and financial pressure on households and businesses.

In addition to medical expense insurance, "health insurance" may also refer to insurance covering disability or long-term nursing or custodial care needs. Different health insurance provides different levels of financial protection and the scope of coverage can vary widely, with more than 40 percent of insured individuals reporting that their plans do not adequately meet their needs as of 2009

- What is the present level of services in the community?

- What is the current distribution of services in the community (to social groups or to neighborhoods)?

- What are the anticipated needs and accessibility to services of the future population?

$$
\sim 291 \sim
$$


- Are there organizational or coordination problems currently being encountered by service organizations or agencies?

- May such problems are encountered in future service delivery? If so, what are they?

- What are the implications of future service and facility requirements and revenue sources on tax levels, net fiscal balance and service quality?

In a more technical sense, the term is used to describe any form of insurance that provides protection against the costs of medical services. This usage includes private insurance and social insurance programs such as Medicare, which pools resources and spreads the financial risk associated with major medical expenses across the entire population to protect everyone, as well as social welfare programs such as Medicaid and the State Children's Health Insurance Program, which provide assistance to people who cannot afford health coverage.

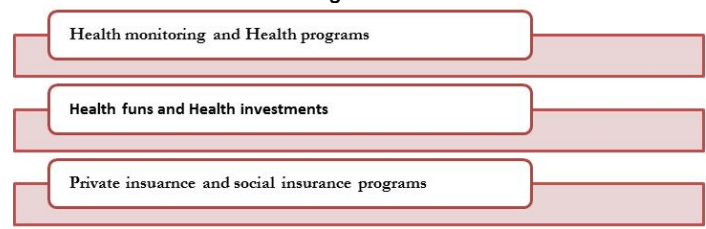

Source: State Children's Health Insurance Program, internet link,wwwfocus,isksh

\subsection{Health Care Project of Development and Objectives (PDO)}

New programs, from mentoring to training to individual consulting support, can help support our next generation of development leaders, no matter where they are from. The National Health Accounts 2003 estimate that Albania spent 43.8 billion Lek (USD 360 million) overall on the health sector and per capita expenditures of 13,983 Lek (USD 114.7). The total expenditure on health is 5.9 percent of the GDP and is significantly higher than previous estimates that had placed health care expenditures at $2.9 \%$ of GDP. This level of expenditure is more in line with middle income countries and is lower than the average for European neighbor's countries. These partnerships do not mean that we write blank checks to foreign governments. Assessments are used to identify specific institutions that will be good partners. In some cases, we may only partially use the partner's system in order to strengthen it while maintaining financial controls and mitigating risks. In Albania case study, we partnered directly with the Ministry of Health to build it into an institution capable of serving its people and sustaining results beyond our assistance, but we limited our use of its systems to those that met our fiduciary standards

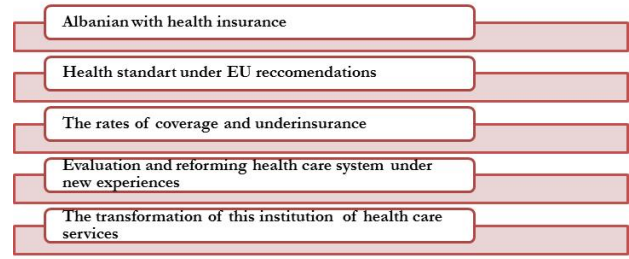

Source: The stability and influences in health care system Dumi A 2013, MJESS Roma Italy

The transformation of this institution into the single payer of health care services in the country, will enable a better management of available financial resources, will promote the process of contracting with providers in order that services are offered based on service packages. Evaluation recommendations from a health care financing project in Albania were used to improve the follow on program by including the use of both public health and finance professionals and establishing a clearer performance-based system. The attitudes community residents have toward development and the specific actions being proposed as well as their perceptions of community and personal well-being are important determinants of the social effects of a proposed action.

Such attitudes are a reflection of the quality of life residents seek to enjoy and preserve, whether it be limiting growth in order to maintain the rural image of a small community; expanding the boundaries of the village; or providing a variety of housing choices to new, diverse residents and businesses. Changes in a community's social well-being can be determined by asking the individuals and representatives of groups or neighborhoods in the area to make explicit their perceptions and attitudes about the anticipated changes in the social environment. (Chadwick, A. 1995)

The Health Insurance Institute (HII) has made significant progress over the last 15 years to movetoward a single-payer model for the implementation of compulsory health insurance coverage inAlbania. This progress has been made in coordination with a national strategy for health reform bythe Government of Albania (GOA), the Ministry of Health (MOH), and other GOA and healthsector institutions.

\section{Macroeconomic stability and influences in health care system}

The imperfections in the health care market imply that governments must play an important role. However, there is no single model 
that delivers the best results across all countries. The pervasiveness of market failures and a desire to ensure that access to basic health care reflects need and not ability to pay have motivated extensive government involvement in this sector in advanced and emerging economies (Musgrove, 1996). The nature of government intervention (e.g., mandates, regulations, provision, and financing) has varied substantially across countries and over time, as has the level of public health spending.

(The economics of public health care reform in advanced and emerging economies / editors, Benedict Clements, David Coady, and Sanjeev Gupta. - Washington, D.C)

International Monetary Fund, 2012According to preliminary data, economic growth slowed to $1.6 \%$ in 2012 from $3.1 \%$ a year earlier. Financial constraints, low confidence among consumers and investors and the presence of spare production capacity held back private consumption and investment spending. Total gross fixed capital formation decreased by around $5 \%$ in 2012 compared with the previous year. Migrant workers' remittances increased slightly, by some $1.6 \%$ in 2012, but dropped by $33 \%$ on an annual basis in the first six months of 2013. Private consumption remained at low levels. (Commission working document, Albania Brusel 2014)

Net exports were the main contributor to economic growth, with foreign sales holding up while imports declined. After falling in four consecutive quarters, economic sentiment indicators started to climb in late 2012 and early 2013, but real GDP only grew by $1.7 \%$ in the first quarter of 2013 in annual terms, reflecting still sluggish domestic spending. Foreign demand continued to contribute positively to growth.

The share of Albanian with health insurance has been steadily declining since at least 2000 . As of 2010 just fewer than $64 \%$ of Albanian had some form of health insurance, which meant that more than 4 million people went without coverage for at least part of the year. Declining rates of coverage and underinsurance are largely attributable to rising insurance costs and high unemployment. As the pool of people with private health insurance has shrunk, Albanian is increasingly reliant on public insurance. Public programs now cover $31 \%$ of the population and are responsible for $44 \%$ of health care spending. Public insurance programs tend to cover more vulnerable people with greater health care needs. (Internet link, 2012)

The process of health reform and health insurance development has beensupported by the United States Agency for International Development (USAID), the World Bank(WB), the European Union, and others. While the overall health reform efforts in Albania haveperhaps evolved slower than envisioned, HII has pushed forward to develop and implement newreimbursement schemes for pharmaceuticals and primary health care ( $\mathrm{PHC}$ ) centers. Recently, HII has moved into payments to the secondary and tertiary hospital sector, ensuring that it will play an increasingly critical role in the health reform process in Albania. " The current situation concerning our insurance scheme, developments in financing the primary health care and hospital sectors, our future projects to improve the way of financing hospital services, etc. were displayed in this presentation. Our learning and evaluation team reviewed every incoming evaluation to ensure that it met the quality standards in our policy.

The review was conducted in April-May 2011. The methodology used for the review consisted of:

- Collection and review of background documents prior to field work;

- Meetings to discuss objectives and processes with the EEHR team at the project office;

- Interviews with USAID and other counterparts;

- Interviews and data collection with key stakeholders at $\mathrm{HII}, \mathrm{MOH}$, and other relevant health

- sector institutions;

- Site visits to regional facilities (Shkodra) and a private hospital in order to observe conditions

- and discuss various issues, relationships, roles, and responsibilities; and

- Analysis of findings and presentation of recommendations.

Given the increasing incidence of breast cancer disease and considering the important social policy struggle against this disease, we have set an important indicator for screening $80 \%$ of women at an age of risk (over 35 years) by the family physicians.

\section{The indicators of quality service in diabets patients.}

This indicator, which is now part of the indicators of quality service, has been added so that the disease is caught in time, the increasing success of the treatment of these cases and decrease of mortality.also, another indicator of quality that has been added to the contract, has to do with a better examination of patients suffering from diabetes, taking account of the fact that this is a disease in expansion (we treat about 510 new cases per month) and with major consequences for the population.A local health finance specialist was deployed prior to the arrival of two international consultants to perform the initial identification, collection, and review of documents relevant to Hll's evolving history and mission, organizational structure, processes, and relationship with other health sector institutions.

The consultants reviewed over 100 laws, Council of Minister decisions, reports, papers,and documents for this report. Building on this work, the consultant team met with key local stakeholder institutions and others to construct a draft description and analysis of HIl'soperational/functional relationship with the $\mathrm{MOH}$, other key health institutions, PHC facilities,hospitals, the private sector, Ministry of Finance (MOF), the Prime Minister's Office, and other government and civil society stakeholders. The institutional review team also carried out a review (not an audit) of the various departmental and section functions and activities of HII. only in certain periods of time, when the hospital is unable to provide to the hospitalized patients, drugs and other medical materials, their 
prescriptions of purchase outside the hospital must be signed by the head of service and the patients' physician. in these cases, the patient's physician, writes a $p$ (which means personal) on file aside the drug / drugs and other medical materials used by the patient.The team reviewed formal departmental descriptions,interviewed departmental personnel and discussed systems, problems, and issues with them. Theteam reviewed documents and key functions and tasks of each department. Lastly, the team travelledto one region, meeting with the HII office to review their operations, visiting a regional hospital and a municipal health center, and meeting with other stakeholders in both the public and private sectors.

\subsection{Disscussion of general findings}

When evaluations failed to meet the standard, the three most common concerns were: (1) evaluation teams received too many questions - especially questions that are too general and ill-defined-relative to the resources available for the evaluation, (2) the data collection and analysis methods were not appropriate to answer the evaluation questions, or (3) evaluation reports did not clearly demonstrate how evidence led to new findings and conclusions. Given these findings, we need to increasingly focus on taking early action to improve the quality of our evaluations. Ultimately, the goal isn't to prove we're always successful. It's to help us learn and get better as an organization HII representatives explained in their presentations the new policies of Albanian Government and HII for improving our health system; perspectives of changing the financing of the health scheme from based on contributions into the general taxation.

In the area of consumer protection, with regard to horizontal aspects, the 2013-20 consumer protection and market surveillance strategy is awaiting adoption. The Consumer Protection Commission (CPC) has held regular meetings and has handled complaints in the fields of university education, the electricity sector and telecommunications. A gap analysis on the alignment of Albanian legislation with the acquis in the field of consumer protection was finalised, including components on health protection. The $\mathrm{CPC}$ and the Consumer Protection Unit continued their consumer awareness activities.

\section{The perspectives of changing the financing of the health scheme}

The online complaint handling system has not generated effective complaints due to the poor information provided to users. Information on the CPC official website is not regularly updated. The gradual transformation of HII into a National Health Service and the fact that National Health Service will be the only payer of health services in the country occupied an important place in Albania. The effective implementation of the new Law on Compulsory Health Care Insurance, as well as the future of national health reform efforts, will depend strongly on the future success of HIIThe Albanian Household is the major financer of health sector $60 \%$ of total health expenditures (THE) with the Government of Albania share providing approximately $34 \%$. Most important, we have to continue prioritizing our people-the greatest resource we have-by systematically identifying opportunities for professional growth and development. While many Mentoring the Next Generation of USAID LeadersUSAID's Bureau for Europe \& Eurasia is bridging the gap between our past and future leaders through a formal mentoring program between Agency alumni and mission staff. Alumni were matched for dedicated coaching and mentoring with mid-level managers assuming new and higher-level responsibilities.

It is important to bear in mind that while certain individuals or community groups may be active and forthcoming with input into the planning process, other community groups (e.g., low income or minority groups) that may be equally or even disproportionately affected by the proposed development may be less vocal in expressing concerns and interests. In situations where traditionally disempowered groups may be impacted by a development, it is important to make a concerted effort to involve them in the social impact assessment process.

\subsection{Promoting sustainable development throught high impact of partnership}

Our investments helped expand access to basic services from only nine percent to 64 percent of the country, leading to the largest increase in life expectancy and largest decreases in maternal and child mortality of any country in the world in the last decadeThe fact that we have an older population is not the only reason for the continuous increase of our costs, but also because all the people generally think that the most expensive service is the best service. The lack of capacity in healthcare management, low public spending and corruption has slowed down progress in the area of public health. Primary healthcare lacks appropriate funding and human resources. The coverage of insurance-based care is still very low. The public hospital sector remains underdeveloped whereas the private sector is growing without proper regulation. The Ministry of Health signed a contract in January for the establishment of a National Electronic Health Record (NEHR) system but the necessary financial resources still need to be secured. The draft e-health strategy has not yet been adopted.

For one reason or another, the services have started to be fragmented and a higher priority is given to the quantity than to the quality. that the health insurance scheme currently includes all vulnerable categories, categories which are covered by the state. so in addition to the direct contributors in the scheme, the Government is responsible to the categories in need such as pensioners (about 230 thousand beneficiaries per month), invalids (about 45 thousand every month), etc., which benefit at $100 \%$ free of charge health services. actually, the universal coverage is based on the insurance scheme in albania and it is clearly constituted in the new health insurance law, which covers the entire population in need such as pensioners, veterans, unemployed etc.-categories that are covered at $100 \%$ by our insurance scheme. 
With regard to communicable diseases, a new draft Law on the control of infectious diseases remains to be adopted and national guidelines on antimicrobial resistance are being drafted. At the national level, reported immunisation coverage for 2012 was over $98 \%$. The Ministry of Health established a national committee and a secretariat for reactions after vaccination. Awarenessraising activities, mainly targeting Roma, were carried out. Implementing legislation ensuring the right to health for persons and children living with HIVIAIDS and people at risk is still awaiting adoption. Laboratory capacity requires improvement.this social scheme is further clarified in the new law, according to which, in addition to the economically active persons which are insured, the compulsory health insurance covers also the categories in need, such as pensioners, invalids, veterans, people receiving social assistance, unemployed, pregnant women, foreigners asylum-seekers in the republic of albania, children under the age of 18 years, pupils and students under the age of 25 years, provided that they do not have incomes from economic activities; as well as the categories defined by special laws. For all these categories as well as for those categories defined by special laws, the state contributes."

For this reason, there is an immediate need to create service packages, which are provided for in this law. These packages will be well defined and will be too much transparent, something that is expected to eradicate corruption. Transparency will be applied in every chain of the system and for every type of service starting from the introduction of the patient in the system up to the costs paid by the Fund for patients. The proportion of government budget allocated to health sector is a little over 7.5 percent. Public sources account for 34 percent, private sources for 62 percent of health care financing and international donors for the remaining 4 percent. The largest source of financing comes from households which represents 60 percent of total expenditures. In terms of expenditures, private pharmacies are the major provider of health services.(Hazam, Dhamo,Kola 2005)

\section{Conclusions}

The following recommendations emerged from this institutional review of HII. The consultant team encourages Albanian stakeholders to review and discuss the recommendations in light of the sector's health reform strategy, future plans, and available resources. Recommendations may be discussed within HII, among other health sector stakeholders including the MOH and NCQSA, and even by the Prime Minister's task force or at other Government levels as appropriate. the Health care insurance institute has approved the new contracts with health services providers of all levels for 2013, putting the emphasis on funding at best the health centers based on the quality provided to patients, extraction of hospital services' costs and stricter controls for reimbursable drugs from the contracted pharmacies.

HII needs to develop a more comprehensive "vision" of its new emerging role, responsibilities, and functions within the wider national context of compulsory health insurance coverage for all of the population. Funds to be used by hii for drugs reimbursement this year are expected to reach a total of 8.4 billion of (new) lek, i.e. about 500 million lek more than a year ago. this fund is 2.5 times higher than the fund spent on the drugs' list in 2006, when 3.4 billion lek was spent on drugs (Isksh Focus, 2013)This could be carried out through a strategic planning process that would bring together key stakeholders including $\mathrm{MOH}$, HII Administrative Council and management, and hospital and health center representatives, to engage in a highly interactive process of environmental assessment(Strengths, Weakness, Opportunities and Threats), discussion of critical issues facing HII,development of strategic objectives to effectively address critical issues identified, and finally development of work plans for the next 3-5 years.

\section{References}

Arieh Goldman "stages in the development of the supermarket "Juornalof retailing 51 pp 49-66

Branch, K., .A. Hooper, J.Thompson, and J. Creighton 1984. Guide to Social Assessment: A Framework for Assessing Social Change. Westview Press: Boulder. Burdge, R.J. 1995. A Community Guide to Social Impact Assessment.University of Illinois: Urbana.

Burdge, R.J., P. Fricke, K. Finsterbusch, W.R. Freudenberg, R. Gramling, A. Holden, L. Llewellyn, J.S. Petterson, J. Thompson, and G. Williams. 1995. Guidelines and Principles for Social Impact Assessment. Environmental Impact and Assessment Review. 15:11-43. Elsevier Science, Inc.: New York.

Bill Saporito 2006 "The fix is in at home depot "Fortune 1998 pp 73-74,79 "The discount industrys top 150 Chains p 35. The economics of public health care reform in advanced and emerging economies / editors,

Canter, L. W. 1985. Socio-economic Factors Used in Environmental Impact Studies. In Canter L.W., Impact of Growth: A Guide for Socio-economic Impact Assessment and Planning, pp. 328-394. Lewis Publishers: Chelsea, Ml.

Chadwick, A. 1995.Socio-economic Impacts 2: Social Impacts. In Morris, P. And R. Therivel, Methods of Environmental Impact Assessment, pp. $29-49$. University of British Columbia Press: Vancouver.

Chenoweth, R. 1999. Integrating information technologies for citizen-based land use decision-making. College of Agricultural and Life Sciences, University of Wisconsin

Christensen, K. Social Impacts of Land Development: An Initial Approach for Estimating Impacts on Neighborhood Usages and Perceptions.

David P.Schultz " The top 100 Specialty Stores August 1990 pp 9-17 Exec 100 "p 40

Richard Anderson "That roar you hear is food lion "Business Week August 241987 pp 65-66 "58thAnnual report "Progresive grocer April 1991 p 8 Exes $100 p 43$

Frances Brown "Convenience stores move to diversify" The wall street journal "September 121984 The census of retail trade published by the US

Penny Gill "whats a department store "store February1990 pp 8-17

The discount industry s top 150 Chains "discount store news July 221992 p 35

Joseph Pereira "Discount Department Stores Struggle Against Rivals that strike Aisle by Aisle "The wall Street Journal June 191990 pp b1 b7 The discount Industrys top 150 chains "Discount Store News July 221991 p 35

Jack G. Kaikati "The boom in Warehouse Clubs "Business Horizons April 1987 pp 68-73“Superstore Retailing "stores July 1989 pp 40-45

William Saponto "The Mad Rush to join the warehouse club"'Fortune January 6 1986pp 56 "Fast inventory turns Payoff "Chain store age Executive" November 1989pp 24 